\title{
Dr Ramazzini (1633-1714) and the occupational diseases of midwives and wet nurses
}

\author{
Peter M Dunn
}

Bernardino Ramazzini was born in Carpi near Modina in Italy in 1633. He studied medicine in Parma and took his doctorate in 1659. After a year with Dr Rossi in Rome, he practised for some years in the province of Viterbo until a severe bout of malaria caused him to return to his home town. On recovering he married Francesca Righi. They had a son who died in infancy and two daughters.

Carpi served as a summer resort for many of the leading families of Modina. Impressing them with his learning and charm, Ramazzini was invited in 1671 to move to the city where he quickly gained the patronage of the ruling d'Este family. In 1678 Duke Francesco II founded a university in Modina and Ramazzini was appointed Professor of the Theory of Medicine, a post that he held for the next 22 years. We are told that Ramazzini was a lean man of sallow complexion with black hair that became prematurely white and was concealed by an elegant wig. He dressed well and walked so fast that his students had difficulty in keeping up with him. Games he avoided but he thoroughly enjoyed playing chess. He paid little attention to the affairs of the household but in all else was a hard worker and a keen observer.

In 1700 Ramazzini was persuaded to accept the Chair of Practical Medicine in Padua. He was 67. In 1707 he was made President of the Venetian College and two years later became Primarii of the medical faculty. But by this time his health and eye sight were failing and in 1714 he suffered a severe apoplexy. Dr Morgagni and other colleagues hastened to his bedside but he died a few hours later. $\mathrm{He}$ was 82. His body was laid to rest in the Church of the Nuns of St Helena in Padua.

Dr Ramazzini, a contemporary of Malpighi and Leibnitz with whom he corresponded regularly, was one of the great figures of 17 th century Italian medicine. Besides being a scholar and clinician he studied barometry and hydrostatics. He was also a distinguished hygienist and epidemiologist in the Hippocratic mould. Indeed, on being elected a member of the Viennese Academy of Curiosi Naturae in 1691, he was given the name of 'Hippocrates III'. However, it was for his work on occupational diseases that he is best remembered. His magnum opus called the Diseases of Workers, first published in 1700 and expanded in 1713, is a medical classic. ${ }^{1}$ It deals with the diseases of over 50 different

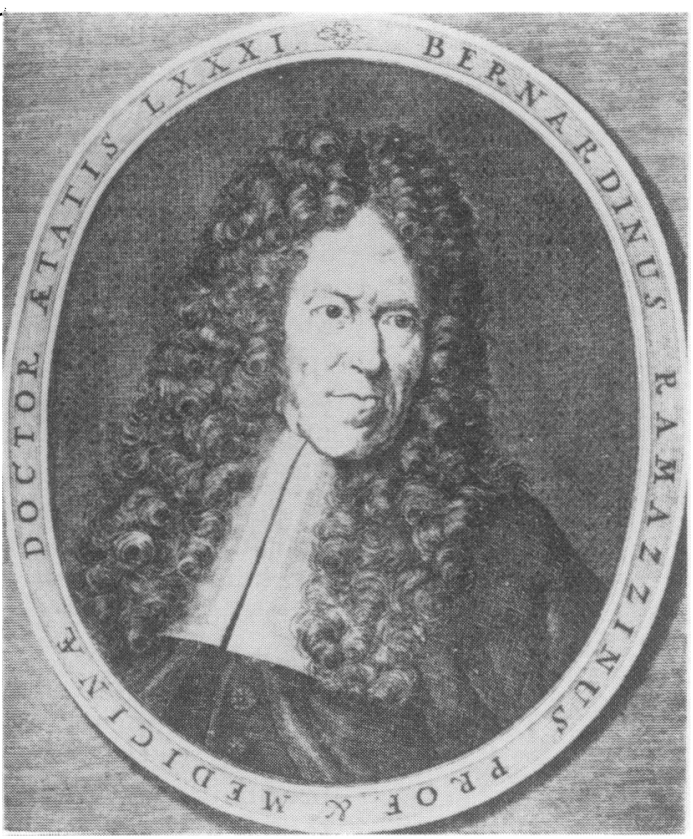

Dr Bernardino Ramazzini (1633-1714).

occupations such as the glass workers and mirror makers, the blacksmiths, the apothecaries, and the cleaners of privies and cess pits. There is also a chapter on the diseases of learned men, of whom he wrote:

'. . nearly all learned men ... suffer the drawbacks of a sedentary life; but I except medical practitioners. It is commonplace that to become erudite you must keep sitting; so day and night they sit absorbed in the delights of study and oblivious of the harm done to their bodies, until the unheeded causes of diseases steal in on them little by little and confine them to their beds. I have already indicated above the disorders brought on by a sedentary life, so I shall not dwell on this further ... Of all who follow the learned professions, those who are most exhausted by their studies are men who are preparing to publish an edition of their own works and have set their hearts on winning immortal renown. But I mean only those who are truly learned, for very many are possessed by a mania for writing and hurry to publish stuff that is badly put together, abortions rather than the mature offspring of their brains. They are like certain poets who dash off a century of poems, 'standing on one foot', as Horace says. Now 
the truly learned who look forward to winning for their names fame and renown that will last long, wear themselves out by working day and night so that sometimes they die before they bring forth'.

Ramazzini's book also contains chapters of the diseases affecting midwives and wet nurses from which the following extracts are taken:

\section{ON MIDWIVES}

'. . . there is no possible doubt that the uterine flux that precedes and follows a birth possesses a malignant and poisonous quality, as is evident where there is sudden suppression or diminished flow of the lochia . . . Now while the women in labor are seated on the chair, the midwives stand by leaning forwards with hands outstretched to receive the infant, and they keep standing at this task for several hours; hence from the dripping lochia they suffer such serious injury to their hands that these sometimes become inflamed and ulcerated by that corrosive, acrid matter. Fernel, marvelling at the virulence of contagious diseases, cites the case of a midwife who, while attending a confinement, contracted so serious a lesion in her hand that it finally rotted and fell off; however, he does say that the patient was infected with the French disease [syphilis] . . . How, then, shall the medical profession safeguard and deliver these women when they deliver, how assist them to follow their calling with all possible impunity? The only way is for them to wash their hands and arms in water or wine when they have a breathing spell; when their work is done they should wash the face and rinse the throat with vinegar and water, put on clean clothes when they go home, in short be very careful to keep themselves clean. I was told by an aged midwife that, whenever she attended a woman who was either suspected of suffering from the French disease or was in any way sickly, she used to wait till the patient was in the very last throes before she placed her on the chair; this was to shorten the time in which her own hands would be wetted by the contaminated lochia'.

\section{ON WET NURSES}

Concerning sexual intercourse: '. . . nurses are liable to hysterical troubles, particularly those who live in the houses of the great and eat rich succulent food but are carefully guarded from intercourse with their husbands ... Nearly all writers on the regimen of nurses accept as beyond question, as a sort of oracular utterance, the doctrine that a nurse ought to abstain from sexual intercourse or her milk will be spoiled . . . yet I regard it as not only against reason, but $I$ have myself observed that it does not conduce to health and is contrary to experience ... . Now I should not venture to deny that sexual intercourse if immoderate and frequent must taint the milk somewhat; but perhaps the truth is that it is spoiled even more if nurses who are suckling infants in other people's homes are deprived of intercourse with and even the sight of their husbands, so that they cannot visit their own homes and children; this only makes them long the more for that forbidden intercourse, and from brooding over their troubles night and day they fall into fits of violent hysterics .

.. For I observe that among the common people mothers always nurse their infants, unless prevented by some accident, and they sleep every night with their husbands and do not abstain from the usual sexual intercourse; yet there is no evidence that this does any such harm by spoiling the milk as doctors apprehend and imagine when they prescribe strict chastity for those who are nurses in the houses of the nobility and princes ... The fact is that in this city very few of the nobility employ nurses in their houses because high living makes them unbearably immodest and saucy . . . Hence they nearly always hand them over to nurses who rear them in their homes along with their own children, but they prefer to entrust them to country women rather than to women of the city so that they may be nourished on richer milk'.

Concerning the sympathy between breasts and uterus: 'We must certainly believe that the Divine Architect fashioned the uterus and the breasts with some structure, some contrivance that so far escapes us, so designed that by an established routine conception in the uterus is followed by the generation of milk in the breasts, on the analogy of what we now know happens when the fetus breaks out of its prison, and its lungs, which for nine months had nothing to do, thereupon enter on their function as the outer air begins to enter the mouth and to inflate them by its elastic force; so that simultaneously the foremen ovale falls into disuse and the blood circulates by other channels. We must therefore concede that a marvellous sympathy between the breasts and the uterus does exist; but so far it has not been explained by the sagacity of man or come under the eye of the anatomist ... This marvellous sympathy of the breasts and uterus, those two sources of desire, is amply demonstrated when the nipples are rubbed, for this, as women admit, is a strong incentive to venery. Carpi says that handling the breasts, especially the nipples which become erect like the penis, stimulates languid desire'.

Concerning too frequent breast feeds: 'I cannot take leave of nurses without suggesting to them one very important precaution to be followed in their own and the child's regimen, which is that they must not be too generous with their milk and give the infant the breast too often or whenever it cries. This is a very common mistake of theirs, I mean that they will give the infants milk a hundred times a day and more often in the night so as not to hear them cry, and the result is that they gradually wear themselves out and overloaded the child with milk so that both nurse and child become wretchedly ill. How can that tender little stomach deal with all that milk and not 
suffer from indigestion, acidity, clotting, and frequent vomiting? How can the nurse fail to waste away from that incessant suckling? Our peasant women are certainly more prudent about nursing their children, for they give them the breast only three or four times a day and leave them to cry as much as they please while they themselves are busy at work in the fields'.

Perhaps the most remarkable aspect of Ramazzini's writing was his emphasis on the prevention of disease, a theme that remained generally neglected by the therapeutically orientated medical profession almost up to the present day. Nor were his clients any more responsive than they are today. In vain did he recommend personal cleanliness, the luxury of clean clothes on holidays, moderation in food, drink, and exercise, and warn of the danger when, scantily clothed, they left overheated workshops for the chilly streets.

Ramazzini B. Diseases of workers, 1713. Translated by W C Wright. Chicago: University of Chicago Press, 1940.

\section{LETTERS TO THE EDITOR}

\section{Metabolic acidosis in premature babies}

SIR,-Walter recently reviewed metabolic acidosis in newborns, however little mention was made concerning volume expansion as a possible treatment strategy. ${ }^{1}$ In particular the role of human albumin solution (HAS) in ventilated, premature babies was not discussed.

We have studied the effect of an infusion of $15 \mathrm{ml} / \mathrm{kg}$ of $4.5 \%$ HAS, over 30 minutes, in 19 consecutive low birthweight infants receiving mechanical ventilation with a metabolic acidosis. Arterial blood was taken before and 15 minutes after volume expansion for the measurement of $\mathrm{pH}$, base deficit, bicarbonate, and lactate (table). During the study ventilatory requirements remained stable.

The significant rise in $\mathrm{pH}(\mathrm{p}<0.01)$ and significant decrease in base deficit $(p<0.0001)$ was mirrored by a significant decrease in serum lactate $(p<0.001)$, interestingly there was no change in serum bicarbonate (paired $t$ test).

This study shows that lactate accumulation, probably the result of hypovolaemic tissue hypoxia, is a cause of metabolic acidosis in premature babies. This acidosis is appropriately rectified by the infusion of a volume expander.

E J KELLY K G BROWNLEE M J HENDERSON* P R F DEAR Department of Paediatrics and Child Health and Department of Chemical Pathology,* St fames's University Hospital, Beckett Street
Leeds LS9 7FT

1 Walter JH. Metabolic acidosis in newborn infants. Arch Dis Child 1992;67:767-70.
Traumatic neonatal intracranial bleeding and stroke

SIR,-Extending the concept of posterior cerebral artery compression associated with intracranial hypertension to other arterial distributions in the expansile neonatal skull requires reasonable proof. We believe that discrepancies in the radiological and clinical data presented by Govaert et al limit the strength of their final suggestion. ${ }^{1}$

Direct demonstrations of arterial injury associated with intracranial hypertension are not presented. Several computed tomograms are misinterpreted, for example fig 1 does not show a 'basal convexity' haematoma while anatomically inaccurate interpretations are given for fig $6 \mathrm{~B}$. In fig 3 , the haematoma is located at the level of the tentorium while the computed tomogram demonstrates a hypodensity in the territory of the proximal middle cerebral artery. This anatomical discrepancy is continued in the schematic drawing. Either the initial (case 5) or follow up (case 6) computed tomograms are not presented and consequently adequate conclusions may not be reached concerning the aetiology of the computed tomogram abnormalities. Finally, alternative clinical explanations for the computed tomogram finding such as a watershed infarct in case 1 or intraparenchymal injuries in cases 2 and 7 are ignored or discarded without sufficient cause.

Most of these infants demonstrated several neuroradiological abnormalities. Ascribing long term sequelae to one or the other may be inaccurate and legally treacherous. More importantly, the natural but inappropriate desire to correct surgically any potential problems implied by these data should be resisted until newer techniques such as magnetic resonance angiography can confirm the authors' speculations.

WILLIAM C HANIGAN WILLIAM C OLIVERO TIM C MILLER The University of Illinois College of Medicine, Department of Neurosciences, PO Box 1649 Illinois 61656-1649

Effect of $4.5 \%$ HAS infusion in 19 low birthweight infants. Results are mean (SE)

\begin{tabular}{lllll}
\hline & $p H$ & $\begin{array}{l}\text { Base deficit } \\
(\text { mmoll })\end{array}$ & $\begin{array}{l}\text { Serum bicarbonate } \\
(\text { mmoll })\end{array}$ & $\begin{array}{l}\text { Serum lactate } \\
(\text { mmol })\end{array}$ \\
\hline $\begin{array}{l}\text { Before infusion } \\
\text { After infusion }\end{array}$ & $7.258(0.023)$ & $\begin{array}{l}8.98(0.82) \\
7.53(0.79)\end{array}$ & $17.37(0.62)$ & $3.56(0.37)$ \\
\hline
\end{tabular}

1 Govaert P, Vanhaesebrouck P, de Praeter C. Traumatic neonatal bleeding and stroke. Arch Dis Child 1992;67:840-5.

Dr Govaert and coauthors comment

We welcome the interest raised by our article on traumatic neonatal intracranial bleeding and stroke. The essence of our observation was the existence of hypoperfusion within the region of the middle cerebral artery ipsilateral to extracerebral haemorrhage. In the first case of our small series of seven an interval of at least two days between traumatic vacuum delivery (with subgaleal bleeding and supratentorial subdural haematoma) and subsequent hypoperfusion within the middle cerebral artery on that side suggested the possibility of vasospasm as an intermediary mechanism. This was not demonstrated with an angiographical technique and therefore we used the term hypothesis to describe that finding.

We would agree that 'basal convexity haematoma' may be a misnomer. In the absence of generally accepted defining criteria for various types of subdural bleeding we use the term to refer to supratentorial subdural haemorrhage not related to bridging veins of the superior sagittal sinus or to central tentorial injury near the great cerebral vein. Usually these collections are under the temporo-occipital lobe and along the temporal lobe convexity, as was the case in our first patient.The sections used in fig 1 do not show the 'typical' site of bleeding as visible in other sections.

In fig 3 (case 4) a basal subdural haematoma is associated with hypodensity of the mesial temporal lobe. According to all anatomy books we consulted this area is perfused by the posterior cerebral artery. This would not exclude concurrent hypoperfusion of branches of the middle cerebral artery, but we felt our computed tomogram did not show this with certainty. The hypodense areas depicted in fig 1 (case 1) cannot be a watershed arterial infarct according to the same references. It is plainly within the region perfused by the middle cerebral artery.

Some initial or follow up scans were not presented because there is a limitation to the use of scans in an article. We therefore chose to use the most representative scans. The patient in case 6 (fig 5) did not have a follow up scan, because it is our practice to perform scans only on clinical indication.

In case 2 (fig 2) there were three major reasons why we felt the haemorrhage to be 